\title{
The Use of Language Learning Strategies through Smartphones in Improving Learner Autonomy in EFL Reading among Undergraduates in Saudi Arabia
}

\author{
Ali Abbas Falah Alzubi ${ }^{1} \&$ Manjet Kaur Mehar Singh ${ }^{1}$ \\ ${ }^{1}$ School of Languages, Literacies, and Translation, Universiti Sains Malaysia, Penang, Malaysia \\ Correspondence: Ali Abbas Falah Alzubi, School of Languages, Literacies, and Translation, Universiti Sains \\ Malaysia, Penang, Malaysia. E-mail: aliyarmouk2004@gmail.com
}

Received: July 7, 2017 Accepted: August 5, 2017 Online Published: September 24, 2017

doi:10.5539/ijel.v7n6p59 URL: http://doi.org/10.5539/ijel.v7n6p59

\begin{abstract}
Language learning strategies (LLS) and learner autonomy (LA) are believed to achieve a sustainable long-life learning process leading to a more reading competence (O'malley \& Chamot, 1990; Oxford, 1990). LA is a pedagogical imperative inasmuch as language is largely an autonomous activity (Kumaravadivelu, 2006). This study examines the improvement of LA through the explicit use of LLS in EFL reading in a mobile-assisted language learning (MALL) environment among English as a foreign language (EFL) readers enrolled in Preparatory Year program at Najran University in Saudi Arabia. To this end, a questionnaire adapted from Oxford's (1990) Strategy Inventory for Language Learning (SILL), was administered to 32 students to measure their reading strategy use mediated by smartphones in EFL reading context. The data analysis revealed moderate averages $(60 \%)$ of LLS (memory, cognitive, compensation, metacognitive, affective, and social strategies) among EFL undergraduates in EFL reading context. Consequently, these results may restrain the improvement of LA in virtual learning environments, mostly teacherless platforms, where learners need to have these strategies to help them control and manage their own language learning in almost independent learning settings, freedom in time, place, access to resources, and material choices. It is recommended that LA be improved through a strategy use instruction mediated by smartphones in EFL reading context.
\end{abstract}

Keywords: EFL reading, language learning strategies, learner autonomy, Saudi Arabia, smartphones

\section{Introduction}

Coffman \& Klinger (2007, p. 32) claim that the role of education in the 21 st century should pay more attention to "communication, autonomy and control over a student's own learning, and increased innovation and creativity." Due to the calls for student-based learning, this study investigates the use of language learning strategies (LLS) by Oxford (1990) mediated by smartphones to improve learner autonomy (LA) in EFL reading context.

Nowadays the process of language learning is becoming more student-centered learning (Timirbaeva, 2013) as the teacher has become one source of knowledge. The revolution of smartphone technology has left learners flooded with a plethora of texts not only from print but also from varied sources such as the internet (Reoperez, 2011). This plethora of texts necessities that readers are equipped with required strategies that help gradually transform how to express their ideas and learn inside and outside the classroom for more successful interaction and communication with others (Al Hosni, 2013; Scharber, 2009).

One key role to involve learners in language learning process to claim more responsibility is to help them employ the use of LLS in order to know not only what to study but also how to study (Timirbaeva, 2013). Consequently, learners will be able to take control over their language learning process in terms of determining the learning objectives; defining the contents and the progressions; selecting methods and techniques to be used; monitoring the procedure of acquisition (rhythm, time, place, etc.); and evaluating what has been acquired (Holec, 1981, p. 3). The need for involving learners in language learning is due to the many options available today for language learners inside and outside the classroom (Ceylan, 2015).

School students who join university in Saudi Arabia bring with them learning habits such as rote learning, overreliance on teachers, and spoon-fed knowledge (Al-Saadi, 2011). However, EFL undergraduates at 
Preparatory Year at universities in EFL reading course are required to be more responsible for and in control of what they learn. Therefore, having them be aware and apply LLS mediated by smartphones will improve LA in EFL reading context in the sense that learners can acquire a self-mechanism of strategies and practices that help them study and comprehend reading texts on their own.

This study investigates the use of LLS mediated by smartphones in order to improve LA in EFL reading context. It attempts to answer the following questions:

1- To what extent does the use of LLS mediated by smartphones improve LA in EFL reading context among Saudi undergraduates?

2- What are the learners' reflections on the use of LLS mediated by smartphones to improve LA in EFL reading context?

\section{Review of Literature}

\subsection{Language Learning Strategies in EFL Reading Context}

Oxford (1990) defines LLS as "specific actions taken by the learner to make learning easier, faster, more enjoyable, more self-directed, more effective and more transferable to new situations" (p. 8). This definition entails an inner capacity to process foreignlsecond language learning, so learners are more autonomous and less dependent on teacher.

Oxford (1990) and Wenden (1987) argue that LLS involve a number of features that are related to LA. First, LLS allow learners to become more self-directed (autonomous). Second, the teachers' role is expanded to a mediator, facilitator, helper, guide, consultant, and coordinator. They are also problem-oriented and specific actions taken by the learner. Moreover, they involve many aspects of the learner, not just the cognitive; they extend to the metacognitive, affective, and social functions. Further to that, they are often conscious; when learners use LLS, they are aware of what they use and control what they take in learning. LLS are flexible in the sense that learners can have the choice to choose, combine, and sequence strategies. Finally, their choice is affected by many factors such as degree of awareness, gender, stage of learning, task requirements, teacher's expectation, age, ethnicity, learning style, motivation, and purpose for learning the target language.

Oxford's taxonomy of LLS, considered as the most widely used comprehensive classification of learning strategies (Ellis, 1994), includes six main strategies subdivided into a total of 19 strategy sets, thus composing a total of 62 strategies. Oxford (1990) divides LLS into two main strategies: direct and indirect strategies according to the role each group plays in gaining a new language. Direct strategies, which "involve direct learning and use of the subject matter, in this case a new language" (p. 11) are referred to what the learner displays and produces explicitly and subdivided into three groups: memory strategies, cognitive strategies, and compensation strategies. Indirect strategies, which "contribute indirectly but powerfully to learning" (p. 11), refer to the implicit management and direction of the learning process by the learner and are also subdivided into three groups: metacognitive strategies, affective strategies, and social strategies.

According to Oxford's (1990) taxonomy of direct strategies, memory strategies are used for remembering and retrieving new information and include four subcategories: creating mental linkages, applying images and sounds, reviewing well, and employing action. Cognitive strategies are applied to understand and produce the target language and involve the essential processes of practicing, receiving and sending messages, analyzing, and creating structures for input and output. Compensation strategies are about using the language despite knowledge gaps and classified into guessing intelligently and overcoming limitations in speaking and writing.

The indirect strategies in Oxford's taxonomy are used to generally manage language learning. Metacognitive strategies help coordinate the learning process through planning, arranging, focusing, and evaluating their own learning process. Affective strategies, which enable the regulation of emotions, are composed of lowering the learner's anxiety, encouragement, and taking emotional temperatures. Finally, Social strategies are learning with others through asking questions, cooperating, and empathizing. Further illustration comes in the discussion about the questionnaire instrument.

\subsection{Learner Autonomy}

LA in foreign language learning is an independently inclusive process in which learners are responsible for their learning, i.e., they choose materials, set goals, plan well, monitor learning, and finally evaluate achievement (Benson \& Voller, 1997; Holec, 1981; Littlewood, 1996; Pruitt, 2005). These acts of responsibilities, according to Littlewood (1999) assume that learners are fully in charge of their learning because all learning can in any case only be carried out by the learners themselves. 
Holec (1981) conceptualizes the construct of LA in foreignlsecond language learning. He argues that LA is the learner's full responsibility towards the process of language learning and defines it as "the ability to take charge of one's own learning." (p. 3) Holec elaborates this definition in the learner's responsibility for all the decisions concerning all aspects of hisher learning; "determining the objectives; defining the contents and the progressions; selecting methods and techniques to be used; monitoring the procedure of acquisition (rhythm, time, place, etc.); and evaluating what has been acquired". (p. 3)

In the way to LA, Lyddon (2016, p. 305) presents a compromising mechanism amid formal learning constraints. According to him, autonomous learners should possess the following five characteristics: compliance (active participation); competence (following assignment directions); cognizance (understanding the teachers' rationale); introspection (seeing the personal value of the assignment); and diplomacy (negotiating task completion).

Benson \& Voller (1997) see LA as an inborn capacity to explore knowledge, exercises, and activities for more charge of learning, and the learners' right to determine their learning direction. Having LA improved in the domain of EFL reading context requires that certain conditions are obtained: learning strategies (cognitive and metacognitive), motivation and attitudes (perceptions), and knowledge about language learning or self-esteem (the evaluation that the learner makes of himself herself about learning the target language) (Thanasoulas, 2000).

\subsubsection{Oxford's Model of Learner Autonomy}

Oxford (2003) proposes a more comprehensive systematic model including four perspectives; technical, psychological, socio-cultural, and political-critical. This model emphasizes four main themes: context, agency, motivation, and learning strategies. While the technical perspective concentrates on the physical situation and support such as self-access centers, the psychological focuses on the characteristics of the learner. The socio-cultural perspective takes care of mediated learning whereas the political-critical perspective concentrates on ideologies, access, and power structures.

\subsubsection{Technical Perspective}

The technical perspective emphasizes the situational conditions under which LA may develop. Context in technical perspective refers to the availability of knowledge access where learners can fully make use of it whenever they wish. Context could be a real or virtual (online) setting such as a self-access center, a classroom, a home setting, a travel environment, social network, etc. Oxford (2003) highlights the issue of handing over the learning process power to learners by teacher through the use of strategy instruction. Motivation in Oxford's model is an issue of an interactive learning in which learners need to interact with others and wish for guidance. Finally, the technical perspective emphasizes that learners are equipped with strategies to be transferred from the teacher to them, so that they can learn autonomously (Oxford, 2003).

\subsubsection{Psychological Perspective}

The psychological perspective investigates the mental and emotional features of the learners who are seen as either psychologically individuals or as members of a rather generalized social or cultural group (Oxford, 2003).The psychological perspective is a combination of characteristics of the individual. Context in the psychological perspective refers to the context of foreign language learning where it is not the everyday medium of the majority's communication. Oxford (2003) sees agency in the psychological perspective as the "desire to seek meaning; positive attitudes, need for achievement, and a combination of intrinsic and extrinsic motivation" (p. 83). Oxford argues that learning strategies in the psychological perspective are the psychological features of the individual that can change through practice and strategy instruction. Optimal strategy use relates to task, learning style, goals, etc.

\subsubsection{Socio-cultural Perspective}

Oxford (2003) views the socio-cultural perspective as a self-regulation, gained through interaction with more capable, mediating person in a particular setting. Mediating can also be through other means such as book or technology. Context in the socio-cultural perspective is seen as the relationship between learners and more capable others, as well as social and cultural settings. It can also be communities of practice such as school, university, etc. Agency in the socio-cultural perspective is the power to control one's learning through self-regulation and participating actively with other practitioners. Motivation in the socio-cultural perspective is linked to becoming self-regulated individual and part of a community of practice. Learning strategies refer to the strategies that learners employ and learn when interacting with the community of practice (Oxford, 2003).

\subsubsection{Political-Critical Perspective}

Political-critical perspective in Oxford's (2003) model involves gaining access to cultural alternatives and power 
structures; developing an articulate voice amid competing ideologies. Context in the political-critical perspective is arranging ideological positions, instantiated in a specific interaction, relationship, or setting. Agency in the political-critical perspective is the power to control one's situation, be fully heard, be free from oppression, and have choices. Motivation is associated with becoming free to have one's own voice, ideological position, choice of cultural alternatives. The individual is also motivated to seek justice from social inequalities of race, gender, class, etc. Learning strategies can help open access within power structures and cultural alternatives for learners (Oxford, 2003).

\subsection{Language Learning Strategies (LLS) and Learner Autonomy (LA)}

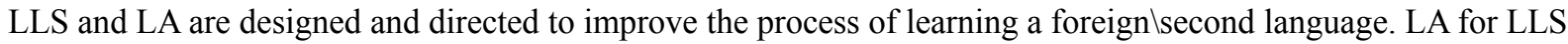
is a feature and goal (Oxford, 1990). Since learning a new language is a lifelong action, learners will need to pass the habitual boundaries of spoon feeding, memorization, and total reliance on teachers as they are just one part of their language learning process scene (Tamer, 2013). Learners of a new language need to be shown how to obtain knowledge and information, interact with others, control their emotions, and be conscious and then automatic. Thus, enhancing language learners with the use of learning strategies will ensure their enough maturity to be autonomous learners in EFL reading context.

LA found its roots in language learning first by Holec (1981). Autonomy stems from the one's purpose and control over his her learning process that can enhance his her needs to know, understand, and extend to the significance and self-actualization (Beach, 1994). Lengkanawati (2014) states that autonomous learning is a situation where learners employ LLS in order to become autonomous. Wenden (1991, p. 15) cited in (Lengkanawati, 2014) affirms the notion of autonomous learners in connection with LLS by saying "learn how to learn to acquire the learning strategies, the knowledge about learning, and the attitudes to use these skills and knowledge confidently, flexibly, appropriately, and independently of a teacher". In connection, autonomy in language can be achieved through LLS (O'malley \& Chamot, 1990; Oxford, 1990; Wenden, 1987, 1998). In order for LA to be improved, Thanasoulas (2000) clarifies that autonomous learning can happen when learners are able to obtain cognitive and metacognitive strategies, motivation, attitudes, and metalanguage. Enough evidence proves the strong link between LLS and LA, i.e. learning strategies are an important key to achieve LA (Ellis, 1994; Hsiao \& Oxford, 2002; Kumaravadivelu, 2006; Oxford, 2008; Wenden, 1985; William \& Burden, 1997).

Holec's (1981) view of learners' charge of learning and operationalization is a reflection of the product of a good language learner through the use of learning strategies (Green \& Oxford, 1995; O'malley \& Chamot, 1990; Oxford, 1990; Wenden, 1998). It is argued that the driving force behind LLS research is actually in their capability to improve new systems of learning in which learners are more autonomous in learning a foreign $/$ second language (Ellis, 1994; Grenfell \& Macaro, 2007; Mahdavi \& Mehrabi, 2013; McDonough, 2002; Williams \& Burden, 1997). As one learning outcome, promoting LA may boost a learner's desire for learning (Littlejohn, 1985), which may, in return, be an important emotional motivating factor to push the learner to continue learning over a long period. In this regard, Nunan (1988) supports the move towards greater LA by stressing the need to provide learners with efficient learning strategies, to assist them to identify their own preferred ways of learning. Hsiao \& Oxford (2002) highlight LLS in their definition of LA. They define LA as willingness to perform a language task with little or no assistance, with flexibility according to the situation, and with transferability to other contexts; and relevant action, including the use of appropriate LLS for accomplishing the task. Oxford (2008) notes that "learning strategies are generally signs of learner autonomy" (p. 52).

LLS can help learners learn effectively, and effective learning motivates learners, so that they become autonomous learners (Oxford, 1990). If students can understand the importance of LLS and be equipped with these strategies as techniques, LA will be improved, and the difficulties encountered while learning language will be less. Hence, language learning will be a pleasurable experience, and the learner will be able to improve a self-directed, independent approach beyond the formal education experience.

\subsection{Smartphones in Foreign Language Learning}

LA correlates with the notion of using smartphones in language learning; the combination of formal and informal learning by Godwin-Jones (2011), learner agency promotion by Vera (2012), proactive responsibility in open and distance learning (Can, 2012). Language learning is considered as a lifelong learning process which requires that traditional academic systems and courses are up to date, so that learners are well-prepared to cope with the rapid pace of technology in the current digital era.

Mobile and smart phone technology has the potential to provide learners with the necessary support in the 
process of autonomous language learning (Reinders \& Hubbard, 2013). The importance of smartphones can be seen in gaining more control over the learning process and connecting with others. Reinders and Hubbard argue that technology would serve the path of LA through providing learners with tools to enable them to control their own language learning. They add that LA can be seen as one channel to link teachers and learners and connect classroom learning with the real world.

The internet and smartphones have made the process of language learning continuous and free of time and place as language is a social component that requires interaction among people, so communication is successful (Chinnery, 2006; Kukulska-Hulme \& Shield, 2008; Sharples, Taylor, \& Vavoula, 2005). Mobile technology integration such as smartphones where learners can claim more roles of control, and teachers act as facilitators of language learning has greatly reduced restrictions on where and when to learn and made available a lot of options in terms of content, interaction, practice, etc. Lyddon (2016, p. 304) argues that the importance of smartphones resides in helping learners "observe and recall things better, fill gaps in our knowledge, and enhance our ability to communicate." Mobile technologies, as not only potential means for learning anywhere and anytime but also channels to rich, multimodal content, provide unprecedented opportunities for the improvement of LA in language learning (Lyddon, 2016).

In conclusion, the related literature has previewed three main constructs: LLS, LA, and smartphones in language learning. Obviously, it is noticed that the use of LLS and LA can have a strong relationship either inside or outside the classroom. Learners can claim responsibility upon their language learning through the use of LLS. However, the employment of LLS requires that learners be well trained to use them effectively and thus act autonomously. In addition, the revolutionary technology of computers, internet, and smartphones has facilitated the process of language learning regarding knowledge access, independent learning, teacherless environment, more learner-centered learning, the practice of language, etc.

\subsection{Related Studies}

White (1995) associated the use of LLS (O’Malley \& Chamot, 1990) and LA (Wenden, 1987) in distance and classroom modes. The analysis of the questionnaire and yoked subject technique (a verbal report procedure) applied to 417 learners (French, German, Japanese and Chinese) enrolled into either distance or classroom modes of study showed that for distance learners, it is the frequent use of a wide range of metacognitive strategies which enable them to improve a degree of autonomy. The findings also revealed that distance learners succeed in overcoming the potentially perverse effects of an isolated language learning context by improving and applying their self-knowledge as language learners. Such individually-derived self-knowledge provides the basis for the use of self-management strategies which appear to be fundamental in the improvement of a more autonomous approach to language learning.

In the Gulf countries of Saudi Arabia, Qatar, and Oman, the use of LLS in relation to certain factors such as language proficiency level, gender, motivation, and duration of study was investigated (Al-Buainain, 2010; Al-Otaibi, 2004; Radwan, 2011). The analysis of the quantitative and qualitative instruments showed moderate use of LLS and relationship with the factors mentioned above in general. One important point is that by Al-Otaibi (2004) who highlighted the importance of language learning strategy program in evaluating whether learners are more motivated, confident, or autonomous during the learning processes and after completing the program.

In three different contexts (Turkey, Indonesia, and Iran), the relationship between LA and computer-assisted language learning (CALL) environments such as Dynamic Education software and BBC Courses was investigated (Farivar \& Rahimi, 2015; Meri, 2012; Rahman, 2013). The results of the data gathered by the questionnaires and interviews indicated that LA is promoted when learners can choose their own learning materials and the way of learning through independent CALL activities.

Timirbaeva (2013) examined the implementation of the course teaching LLS for the students of Kazan National Research Technological University in Russia getting advanced language training at Higher School of Foreign Languages "Lingva". The results showed that the use of LLS increased considerably the motivation of students, promoted creative and cognitive activities. Students knew how to self-study foreign languages, what they should do for that, and what means were to be used. They have become able to construct their own programs and ready to be autonomous learners.

Other studies on the relationship between LLS and LA in conventional classrooms in Turkey and Taiwan were conducted (Ceylan, 2015; Chen \& Pan, 2015) respectively. LLS and LA surveys were applied before and after the strategy use training. The results by Ceylan (2015) showed that the experimental group sometimes use the strategies to remember more effectively, use all their mental processes, to compensate for missing information, to 
organize and evaluate their learning, to manage their emotions, and to learn with others. The study concluded that the more strategies students employ the more frequently autonomous they become by starting to shoulder the responsibility of their own learning process. Chen \& Pan's (2015) study showed a medium level of English learning autonomy and a rare use of strategy. Learners tended to use memory strategies most frequently and affective strategies least frequently. Students seldom participated in English related activities after school. In addition, a correlation was found between learners' learning autonomy levels and LLS.

In a recent study, Alhaysony (2017) investigated the relationship between the use of LLS, gender, and duration of English language study used by 134 Saudi EFL tertiary students. The analysis of the questionnaire adapted from Oxford's (1990) Strategy Inventory for Language Learning (SILL) showed that gender and duration of studying English have been found to affect strategy use, however it was not found significant. In addition, students were low to moderate users of strategies. The results revealed a high preference for cognitive and metacognitive strategies, which assist students in planning and organizing their language learning. Further to that, the results indicated low preference to memory and affective strategies.

In conclusion, the previous studies have examined the effects of some factors such as age, gender, academic major, language proficiency, motivation, learning level, technology, and duration of study on the use of LLS in English as a foreign language (EFL). The related literature of the previous studies conducted in the fields of LA and LLS shows that very few studies have investigated the use of LLS mediated by smartphones both inside and outside the classroom to improve LA in EFL reading context. Therefore, this study explores the use of LLS: direct strategies (memory, cognitive, compensation) and indirect strategies (metacognitive, affective, social) mediated by smartphones in order to improve LA in the technical, psychological, socio-cultural, and political-critical perspectives in EFL reading context. Table 1 shows the relationship between LLS and LA in EFL reading context.

Table 1. The conceptual framework of the study

\begin{tabular}{ll}
\hline LLS in EFL Reading & LA Perspectives \\
\hline Memory strategies & Technical perspective \\
Cognitive strategies & Psychological perspective \\
Compensation strategies & Socio-cultural perspective \\
Metacognitive Strategies & Political-critical perspective \\
Affective strategies & \\
Social strategies & \\
\hline
\end{tabular}

The conceptual framework of the study is operationalized in the sense that the explicit use of LLS (Oxford, 1990) mediated by smartphones will improve LA in the technical, psychological, socio-cultural, and political-critical perspectives (Oxford, 2003) in EFL reading context.

\section{Method}

In this exploratory study, the use of LLS in EFL reading context among EFL undergraduates is investigated. The mixed methods design was applied to a sample of 32 respondents to collect data about the use of LLS in EFL reading through smartphones to improve LA and about students' reflections on the use of LLS mediated by smartphones to learn EFL reading autonomously.

\subsection{Sample of the Study}

A total of 32 randomly selected EFL undergraduates in the reading skills course of level one enrolled in Preparatory Year program (foundation year) at Najran University in Saudi Arabia participated in this study in the second semester 2016/2017. Preparatory Year students share a number of characteristics such as nationality (Saudi), gender (male), age (18 to 20 years old), mother tongue (Arabic), and English educational background (8 years). The students in the science stream at high school join the Preparatory Year (a two-semester program) in which students study English, communication, thinking, research, mathematics, and computer skills. They compete for the medical, engineering, computer science, and administrative science faculties.

\subsection{LLS Questionnaire}

The questionnaire consists of two parts: closed-item and open ended questions.

A- A closed questionnaire on the use of direct and indirect LLS mediated by smartphones was administered to explore the degree of use of these strategies. An adapted questionnaire based on Oxford's (1990) SILL was used. 
The questionnaire includes six main sections: memory strategies, cognitive strategies, compensation strategies, metacognitive strategies, affective strategies, and social strategies. Below each strategy, the sub-strategies are listed. Certain considerations have been taken when developing the questionnaire such as the use of LLS applicable for EFL reading in Oxford's (1990) SILL; the strategies involved in the reading textbook, Interactions 1: Middle East Diamond Edition, published by McGraw-Hill in 2012; the strategies that can be mediated by smartphones. The main purpose of the questionnaire is to measure the use of LLS mediated by smartphones as follows:

1). Memory strategies: strategies of storage and retrieval of mostly new vocabulary words and other information. Some of these strategies include those of grouping, placing words into context, using imagery, etc. This section has 12 items.

2). Cognitive strategies: manipulation or transformation of language. These strategies such as practicing, reasoning, and analyzing contrastively across languages are highly effective for perceiving and producing information. This section has 16 items.

3). Compensation strategies: strategies such as guessing using linguistics and non-linguistic clues would help the learner overcome knowledge gaps and continue with the task at hand. This section has 4 items.

4). Metacognitive strategies: focusing, planning, and evaluating learners' language learning process. They include paying attention, organizing, setting goals, monitoring one's errors, etc. This section has 11 items.

5). Affective strategies: assisting students in controlling their emotions and attitudes and improving self-confidence and perseverance in language learning. Students, for example, make positive statements for self-encouragement. This section has 8 items.

6). Social strategies: helping learners get involved with others, without hesitation, in order to learn the new language. Learners in such cases will probably raise questions, become culturally aware of the second language, and cooperate with their peers. This section has 7 items.

The part of closed-item questionnaire indicates the use of LLS mediated by smartphones in EFL reading on a five-Likert scale: ("1" never, "2" rarely, "3" sometimes, "4" often, "5" always). According to Oxford (1990), a range of 3.5-5 is thought to reflect a high degree of use of that strategy, 2.5-3.4 a medium degree of use, and 1.0-2.4 a low degree of use. Table 2 shows the distribution of LLS, items, and the Cronbach's alpha of the factor groupings of the LLS questionnaire. It can be seen that the overall internal reliability is .94 which can be considered as an excellent degree.

Table 2. Internal consistency of the questionnaire

\begin{tabular}{llll}
\hline LLS & Item & No. of Items & Reliability-Cronbach's Alpha \\
\hline Memory strategies & 1.2 .3 .4 .5 .6 .7 .8 .9 .10 .11 .12 & 12 & 0.79 \\
Cognitive strategies & 13.14 .15 .16 .17 .18 .19 .20 .21 .22 .23 .24 .25 .26 .27 .28 & 16 & 0.85 \\
Compensation strategies & 29.30 .31 .32 & 4 & 0.65 \\
Metacognitive strategies & 33.34 .35 .36 .37 .38 .39 .40 .41 .42 .43 & 11 & 0.87 \\
Affective strategies & 44.45 .46 .47 .48 .49 .50 .51 & 8 & 0.78 \\
Social strategies & 52.53 .54 .55 .56 .57 .58 & 7 & 0.80 \\
Overall & -- & 58 & 0.94 \\
\hline
\end{tabular}

B- Four open-ended questions examined the learners' reflections on the use of LLS mediated by smartphones to improve LA in EFL reading context. The first question (Could you list the smartphone features and applications that help you learn reading skills?) asks for information about the smartphone applications and features that help learn the reading skills. The second question (Are you allowed to use the smartphones inside the classroom?) is about allowing students to use smartphones inside the classroom. The third question (Do you think that you need training on how to employ LLS mediated by smartphones in EFL reading context?), and fourth question (What are the strategies and smartphone features that you think you need training on?) are about the need for training on the best employment of LLS mediated by smartphones in EFL reading context.

The questionnaire copies were distributed to randomly selected students in level one reading classes with the help of teachers in their respective sections in the second semester of the year 201612017.

Data gathered were analyzed using descriptive statistics. The descriptive analysis of Statistical Package for Social Sciences (SPSS) was applied to analyze the survey data. The survey results on the scale were scored and 
analyzed using a 5-point Likert Scale, Weighted Mean, and Standard Deviation (SD). The open-ended questions were analyzed following the thematic analysis approach in which respondents and question themes were systematically coded and then traced (Clarke \& Braun, 2014).

\section{Findings and Discussion}

This section provides the description and analysis of the findings of the study on the strategy use among Saudi EFL students enrolled in Preparatory Year Deanship at Najran University in Saudi Arabia in EFL reading context. In the discussion part, the strategy use results were matched and correlated with the LA perspectives: technical, psychological, socio-cultural, and political-critical. The study question is to what extent does the use of LLS mediated by smartphones improve LA in EFL reading context among Saudi undergraduates?

Table 3. Descriptive statistics of strategy use through smartphones

\begin{tabular}{lllll}
\hline \multirow{2}{*}{ Strategy } & \multicolumn{2}{l}{ Descriptive statistics } & & \\
& Min & Max & Mean & SD \\
\hline Social strategies & 2.78 & 3.53 & 3.22 & .826 \\
Metacognitive strategies & 2.91 & 3.53 & 3.18 & .715 \\
Compensation strategies & 2.94 & 3.34 & 3.11 & .746 \\
Affective strategies & 2.59 & 3.84 & 3.02 & .758 \\
Cognitive strategies & 2.56 & 3.62 & 3.00 & .673 \\
Memory strategies & 2.03 & 3.50 & 2.77 & .647 \\
Overall & & & 3.03 & .591 \\
\hline
\end{tabular}

The respondents were found to be medium users of LLS mediated by smartphones in EFL reading context. The rationale for these results may be attributed to two major issues. First, learners are studying English in an EFL context and as a result do not need it for daily survival (Alhaysony, 2017). Second, the rote learning system makes them more reliant and spoon-fed, where the teachers claim all responsibility for their own learning; the thing that may hinder their reading learning improvement (Al-Saadi, 2011; Tamer, 2013). The medium use of strategy is consistent with those findings by other studies such as Alhaysony (2017), Al-Otaibi (2004), Ceylan (2015), and Chen \& Pan (2015).

As shown in Table 3, social strategies ranked as the most frequently used strategies (mean=3.22, $\mathrm{SD}=.826$ ), followed by metacognitive strategies (mean=3.18, $\mathrm{SD}=.715$ ), compensation strategies (mean=3.11, $\mathrm{SD}=.746$ ), affective strategies (mean $=3.02, \mathrm{SD}=.758$ ), and cognitive strategies (mean=3.00, $\mathrm{SD}=.673$ ); memory strategies were ranked as the least frequently used (mean $=2.77, \mathrm{SD}=.647$ ).

Social strategies, being the most frequently used, are important as they contribute indirectly to learning a foreign language through cooperating and sympathizing with others (Oxford, 1990). Items 54 "Practice English with other students" and 57 "Try to read about the culture of English speakers" were the most frequently used. The recent improvements in curricula, learning, and teaching methods in the educational system and the urgent need for English language learning in Saudi Arabia, especially in the country's 2030 vision support and encourage the role of interactive learning in the improvement of greater linguistic proficiency (Alhaysony, 2017). On the other hand, items 52 "Ask the other person to slow down or say it again if I do not understand something in reading" and 56 "Ask questions about a reading passage" were least used. This finding is inconsistent with the findings by Al-Otaibi (2004) and Alhaysony (2017) who reported cognitive strategies as the most frequently used whereas Al-Buainain (2010) and Radwan (2011) reported metacognitive strategies as most frequently used. Chen and Pan (2015) and Ceylan (2015) ranked memory strategies as most used. That social strategies topped the strategy use can be explained by the assumption that that learners use smartphones mostly to communicate and interact with others either for learning or entertaining purposes.

The second most frequently used strategies were metacognitive strategies. They include planning, organizing, monitoring and evaluating, etc. which help learners exercise control over their language learning (Oxford, 1990). The participants appeared to be moderately familiar with how to manage language learning through the adaptation of the sub-strategies. Strategies of "Notice my mistakes and use that information to help me do better in reading in future" and "Have clear objectives and goals for improving my reading skills" topped the frequent use of this category. However, "Overview the next reading text by previewing questions and vocabulary, and pictures", "Plan my schedule so I will have enough time to read", and "Look for opportunities to read as much as possible" were least used. The findings of high-frequency use of metacognitive strategies in the present study are consistent with those from previous research such as Al-Buainain (2010), Alhaysony (2017), Radwan (2011), 
and White (1995). White (1995) showed that distance learners frequently used a wide range of metacognitive strategies. Distance learners succeeded in overcoming the potentially perverse effects of an isolated language learning context by improving and applying their self-knowledge as language learners

Compensation strategies, which ranked third, enable students to make up for the knowledge gaps (Oxford, 1990). "Try to understand a reading passage without looking up every new word" scored first under this category, followed by "Make up new words if I do not know the right ones while summarizing a passage" and "Use forms of address, background knowledge, text organization, structural clues, and description of people to understand new words in a text". "Understand unfamiliar English words by making guesses using suffixes, prefixes, and word order" had the least frequency. Such findings are in line with other studies such as Al-Buainain (2010), Alhaysony (2017), Al-Otaibi, (2004), Ceylan (2015), and Radwan (2011).

Affective strategies, which are related to controlling attitudes, emotions, and motivation toward language learning, came fourth. Participants in this study least encourage themselves to read even when they are afraid of making mistakes. They can hardly notice when they are tense or nervous. They least use a checklist to discover feelings, attitudes, and motivation after doing a reading task. These findings are consistent with those from previous studies such as Al-Otaibi (2004), Ceylan (2015), and Radwan (2011). However, affective strategies in Al-Buainain (2010) and Alhaysony (2017) reported scored lower means.

In spite of the importance of cognitive strategies in learning a new language, as they are concerned with the language mental processing in terms of perception and production (Oxford, 1990), they ranked fifth. The strategy "Try to translate what I read into my own language in order to understand a reading passage" was mostly used by the participants, followed by "Highlight the major points using colors, underlining, capital letters, circles, bold writing, italics, etc." This finding is consistent with the findings by Al-Otaibi (2004) who likely reported cognitive strategies in the fifth place. The participants least tried to transfer new words in English into their own language to get their meaning and to compare new words in English with words in my Arabic language. Cognitive strategies were found in LLS research as the most popular strategies among L2 learners (Oxford, 1990). Unlikely, Alhaysony (2017) reported cognitive strategies as most used.

Finally, the respondents reported the least use of memory strategies. They most favor to remember a new word by imagining a situation in which the word might be used and categorize related words under one general concept such as weather, nature, sports, study, etc. They least favor to use notes to remember new words and physically act out new words. These results are in line with Alhaysoney (2017), Al-Otaibi (2004), and Radwan (2011) who reported memory strategies as the least used. Alhaysony (2017) attributed the low use of memory strategies in her study to the subjects who were not familiar with the use of mnemonics (specific techniques to enhance memory) and therefore used fewer memory strategies. In this regard, such strategies are largely in keeping with instructional delivery systems typically used by many Arab countries, which are frequently didactic and emphasized rote memorization (Al-Saadi, 2011; Tamer, 2013).

The moderate use of LLS mediated by smartphones reported in this study results in moderate LA in the technical, psychosocial, socio-cultural, and political critical perspectives among EFL undergraduates in EFL reading context. The moderate use of LLS indicates that the learners of EFL reading are less self-regulated, less interactive with the community of practice, and less motivated. These results are supported by Timirbaeva (2013) who reported that students who received training on the use of metacognitive and cognitive strategies increased their motivation, promoted creative and cognitive activities.

The study question what are the learners' reflections on the use of LLS mediated by smartphones to improve LA in EFL reading context?

Respondents were provided with open questions on their reflections on the use of LLS mediated by smartphones to improve LA in EFL reading context. Regarding the first question, respondents provided a list of smartphone features and applications they think they help in learning reading autonomously such as camera, WhatsApp, dictionaries, readers, notes, internet search engines, etc. As for the second question, all the respondents reported that they are not allowed to use smartphones inside the classroom. One student commented on this question saying "they are not allowed, but we use them secretly." In the third and fourth questions, respondents provided that they highly need training on how to employ LLS through smartphones in EFL reading context. Training on the use of cognitive strategies was reported as highly needed, followed by memory and affective strategies. The other three metacognitive, affective, and compensation strategies were least reported respectively.

The findings of the qualitative data analysis would be a basis for real engagement of smartphone features and applications to assist learners in the use of LLS in order to improve LA in EFL reading context. Timirbaeva (2013) emphasized the role of LLS in enhancing the learners' LA in order to motivate them, promote creative 
and cognitive activities, and make advancements in professional fields.

\section{Conclusion}

In the light of the need of the tertiary education in Saudi Arabia for autonomous learning where learners are more responsible for and in control of their language learning, this study explored the use of LLS mediated by smartphones to improve LA in EFL reading context among EFL undergraduates enrolled in Preparatory Year program at Najran University. The data analysis of the questionnaire revealed moderate averages $(60 \%)$ of LLS: social, metacognitive, compensation, affective, cognitive, and memory strategies among learners in EFL reading context respectively. Consequently, these results may restrain the improvement of LA in virtual learning environments where learners need to have these strategies to help them control and manage their language learning in almost independent learning settings, freedom in time, place, access to resources, and material choices in EFL reading context. As a result, the moderate frequencies of LLS reported by the participants result in poor and mid degrees of LA technical, psychological, socio-cultural, and political-critical perspectives. Timirbaeva (2013) argues that "Students who know when and how to use these strategies can be autonomous learners". That is to say the more learners employ LLS in EFL reading, the more their LA is improved. Kumaravadivelu (2006) notices that LA is a pedagogical imperative inasmuch as language is largely an autonomous activity.

In addition, the participants highly stressed the need for training on the use of LLS mediated by smartphones, so they can utilize these strategies when struggling with external texts on their own.

The findings of the study implicate that the moderate use of LLS among Saudi EFL learners can reflect negatively on the use of LA various perspectives. Strategy use instruction could have better chances in fostering the explicit use of LLS and thus improving LA in EFL reading context (Harmer, 2007; Lengkanawati, 2014).

Further empirical research including interventional programs of strategy use mediated by smartphones is highly recommended to improve LA in the technical, psychological, socio-cultural, and political-critical perspectives of Saudi EFL learners in EFL reading context.

\section{References}

Al Hosni, S. S. (2013). MOBILE LEARNING: ENHANCING LEARNING THROUGH CELL PHONES. Doctoral Thesis. Sultan Qaboos University, Oman.

Al-Buainain, H. (2010). Language learning strategies employed by English majors at Qatar University: Questions and queries. An International Journal of Asian Literatures, Cultures and Englishes, 4(2), 92-120.

Alhaysony, M. (2017). Language Learning Strategies Use by Saudi EFL Students: The Effect of Duration of English Language Study and Gender. Theory and Practice in Language Studies, 7(1), 18. https://doi.org/10.17507/tpls.0701.03

Al-Otaibi, G. N. (2004). Language learning strategy use among Saudi EFL students and its relationship to language proficiency level, gender and motivation. Indiana University of Pennsylvania.

Al-Saadi, H. M. (2011). From Spoon Feeding to Self-Feeding: Helping Learners Take Control of Their Own Learning. Arab World English Journal, 2(3), 95-114.

Beach, S. A. (1994). Engagement with Print: Motivation to Read and Learn (Research into Practice). Reading Psychology, 15(1), 69-74.

Benson, P., \& Voller, P. A. (1997). Independence in Language Learning. London: Longman.

Can, T. (2012). Promoting learner autonomy through virtual learning environments. Paper presented at the Akdeniz Language Studies Conference.

Ceylan, N. O. (2015). Fostering learner autonomy. Procedia-Social and Behavioral Sciences, 199, 85-93.

Chen, H. I., \& Pan, H. H. (2015). Learner Autonomy and the Use of Language Learning Strategies in a Taiwanese Junior High School. Journal of Studies in Education, 5(1), 52-64. https://doi.org/10.5296/jse.v5i1.6972

Chinnery, G. M. (2006). Emerging technologies: going to the MALL (Mobile Assisted Language Learning). Language Learning \& Technology, 10(1), 9-16.

Clarke, V., \& Braun, V. (2014). Thematic analysis Encyclopedia of critical psychology (pp. 1947-1952): Springer.

Coffman, T., \& Klinger, M. B. (2007). Utilizing virtual worlds in education: The implications for practice. 
International Journal of Social Sciences, 2(1), 29-33.

Ellis, R. (1994). The study of second language acquisition: Oxford University. https://doi.org/10.1017/s0272263100014479

Farivar, A., \& Rahimi, A. (2015). The impact of CALL on Iranian EFL learners' autonomy. Procedia-Social and Behavioral Sciences, 192, 644-649. https://doi.org/10.1016/j.sbspro.2015.06.112

Godwin-Jones, R. (2011). Emerging technologies: Mobile apps for language learning. Language Learning \& Technology, 15(2), 2-11.

Green, J. M., \& Oxford, R. (1995). A closer look at learning strategies, L2 proficiency, and gender. TESOL Quarterly, 261-297. https://doi.org/10.2307/3587625

Harmer, J. (2007). The practice of English language teaching. Kuala Lumpur: Pearson Education Limited. https://doi.org/10.1177/003368820103200109

Holec, H. (1981). Foreign Language Learning. Oxford: Pergamon Press.

Hsiao, T. Y., \& Oxford, R. L. (2002). Comparing theories of language learning strategies: A confirmatory factor analysis. The Modern Language Journal, 86(3), 368-383. https://doi.org/10.1111/1540-4781.00155

Kukulska-Hulme, A., \& Shield, L. (2008). An overview of mobile assisted language learning: From content delivery to supported collaboration and interaction. ReCALL, 20(3), 271-289. https://doi.org/10.1017/s0958344008000335

Kumaravadivelu. (2006). Understanding language teaching: From method to postmethod. London, New York: Routledge.

Lengkanawati, N. S. (2014). Making EFL learners autonomous: Can language learning strategies help? Paper presented at the 2014 ALAK International Conference "Applied Linguistics in the Era of Multiculturalism", South Korea.

Littlewood, W. (1996). "Autonomy": An anatomy and a framework. System, 24(4), 427-435. https://doi.org/10.1016/s0346-251x(96)00039-5

Littlewood, W. (1999). Defining and developing autonomy in East Asian contexts. Applied Linguistics, 20(1), 71-94.

Lyddon, P. A. (2016). Mobile-assisted language learning and language learner autonomy. CALL communities and culture-short papers from EUROCALL 2016, 302. https://doi.org/10.14705/rpnet.2016.eurocall2016.579

Meri, S. (2012). Autonomous Computer-Assisted Language Learning: Turkish Primary School Students' Perceptions of Dyned Software. Paper presented at the International Conference "ICT For Language Learning".

Nunan, D. (1988). The learner-centred curriculum: A study in second language teaching. Cambridge: Cambridge University Press. https://doi.org/10.1017/cbo9781139524506

O'malley, J. M., \& Chamot, A. U. (1990). Learning strategies in second language acquisition. Cambridge: Cambridge university press. https://doi.org/10.1017/cbo9781139524490

Oxford. (1990). Language learning strategies: what every teacher should know. Boston: Heinle and Heinle.

Oxford. (2003). Toward a more systematic model of L2 learner autonomy. Learner autonomy across cultures (pp. 75-91). Berlin: Springer. https://doi.org/10.1057/9780230504684_5

Oxford. (2008). Hero with a thousand faces: Learner autonomy, learning strategies and learning tactics in independent language learning. Language learning strategies in independent settings, 41-63.

Pruitt, D. (2005). Transactional distance and learner autonomy as predictors of student performance in distance learning courses delivered by three modalities. Unpublished doctoral dissertation, Tulane University, USA.

Radwan, A. A. (2011). Effects of L2 proficiency and gender on choice of language learning strategies by university students majoring in English. The Asian EFL Journal Quarterly, 13(1).

Rahman, M. M. (2013). CALL in promoting EFL learner autonomy at the tertiary level in Bangladesh. Paper presented at the International Conference on Tertiary Education (ICTERC).

Reinders, H., \& Hubbard, P. (2013). CALL and learner autonomy: Affordances and constraints. Contemporary computer assisted language learning, 359-375. 
Scharber, C. (2009). Online book clubs: Bridges between old and new literacies practices. Journal of Adolescent \& Adult Literacy, 52(5), 433-437. https://doi.org/10.1598/jaal.52.5.7

Sharples, M., Taylor, J., \& Vavoula, G. (2005). Towards a theory of mobile learning. Paper presented at the Proceedings of mLearn.

Tamer, O. (2013). Students' Readiness for Autonomous Learning of English as a Foreign Language. Unpublished thesis. University of Sunderland.

Thanasoulas, D. (2000). What is learner autonomy and how can it be fostered. The Internet TESL Journal, 6(11), $37-48$.

Timirbaeva, G. R. (2013). Language learning strategies and their impact on learner autonomy. Paper presented at the 2013 International Conference on Interactive Collaborative Learning (ICL) Kazan National Research Technological University, Kazan, Russia. https://doi.org/10.1109/icl.2013.6644666

Vera, J. E. D. (2012). Left to my own devices: Learner autonomy and mobile-assisted language learning (Vol. 6): Brill. https://doi.org/10.1108/s2041-272x(2012)0000006018

Wenden. (1985). Facilitating Learning Competence: Perspectives on an Expanded Role for Second-Language Teachers. Canadian Modern Language Review, 41(6), 981-990.

Wenden. (1987). How to be a successful language learner: Insights and prescriptions from L2 learners. Learner strategies in language learning, 103117.

Wenden. (1998). Learner Strategies for Learner autonomy. Great Britain. Upper Saddle: Prentic Hall.

White, C. (1995). Autonomy and strategy use in distance foreign language learning: Research findings. System, 23(2), 207-221. https://doi.org/10.1016/0346-251x(95)00009-9

William, M., \& Burden, R. L. (1997). Psychology for language teachers. Cambridge: Cambridge University Press.

\section{Appendix A}

\section{Language Learning Strategies in EFL Reading Context}

This questionnaire is designed to assess you language learning strategies mediated by smartphones to improve learner autonomy in EFL reading context. Read each question and indicate your choice of responses with $(\boldsymbol{V})$ that tells the frequency you do the statement. Then answer the open-ended questions.

1. Never $=I$ do not do it at all.

2. Rarely $=$ I do not do very often.

3. Sometimes $=\mathrm{I}$ do it occasionally.

4. Often $=I$ do it frequently.

5. Always $=\mathrm{I}$ do it at all times.

Does the use of smartphones help

\begin{tabular}{|c|c|c|c|}
\hline \multicolumn{2}{|r|}{ The statement } & \multirow{2}{*}{$\begin{array}{l}\text { Mean } \\
2.77\end{array}$} & \multirow{2}{*}{\begin{tabular}{l|l} 
SD \\
647
\end{tabular}} \\
\hline Me & y Strategies & & \\
\hline 1 & $\begin{array}{l}\text { Classify what I read into meaningful groups such as similarities, opposites, grammar, concrete, abstract, } \\
\text { transportations, etc.? }\end{array}$ & 2.72 & 1.143 \\
\hline 2 & Use new English words in a sentence so I can remember them? & 3.16 & 1.194 \\
\hline 3 & Link new information with what I know making use of sounds, collocations and proverbs in English? & 2.50 & 1.164 \\
\hline 4 & $\begin{array}{l}\text { Connect the sound of a new word and an actual or mental picture of the word to help me remember the } \\
\text { word? }\end{array}$ & 3.06 & 1.268 \\
\hline 5 & Remember a new word by imagining a situation in which the word might be used? & 3.50 & 1.107 \\
\hline 6 & Categorize related words under one general concept such as weather, nature, sports, study, etc.? & 3.31 & 1.203 \\
\hline 7 & $\begin{array}{l}\text { Relate new words to words in my first language that close to new words and then make a mental image } \\
\text { of them? }\end{array}$ & 2.87 & 1.431 \\
\hline 8 & $\begin{array}{l}\text { Use rhymes to remember new words with familiar words or sounds from either English or any } \\
\text { language? }\end{array}$ & 2.53 & 1.077 \\
\hline 9 & Use notes to remember new words? & 2.31 & 1.091 \\
\hline 10 & Physically act out new words? & 2.03 & .861 \\
\hline 11 & Review reading lessons often? & 2.63 & 1.008 \\
\hline 12 & $\begin{array}{l}\text { Remember new words or phrases by remembering their location on the page, on the board, or on a } \\
\text { street sign? }\end{array}$ & 2.66 & 1.428 \\
\hline
\end{tabular}




\begin{tabular}{|c|c|c|c|}
\hline \multicolumn{2}{|c|}{ Cognitive Strategies } & \multirow{2}{*}{$\begin{array}{l}3.00 \\
2.84\end{array}$} & \multirow{2}{*}{$\begin{array}{l}.673 \\
1.221\end{array}$} \\
\hline 13 & Say or listen to new words several times? & & \\
\hline 14 & Try to read like native English speakers? & 2.91 & 1.510 \\
\hline 15 & Use the words I know in different ways? & 3.13 & .907 \\
\hline 16 & Practice the new words and sounds? & 3.09 & 1.279 \\
\hline 17 & Read real texts such as newspapers, magazines, stories? & 2.87 & 1.212 \\
\hline 18 & Write notes, messages, letters, or reports about what I read? & 2.72 & 1.326 \\
\hline 19 & Skim a reading passage, and then scan it for details? & 2.94 & 1.294 \\
\hline 20 & $\begin{array}{l}\text { Use available dictionaries, phrase books, word lists, and grammar books to understand what I read in } \\
\text { the new language and then produce messages? }\end{array}$ & 3.38 & 1.362 \\
\hline 21 & Compare new words in English with words in my Arabic language? & 2.66 & 1.181 \\
\hline 22 & $\begin{array}{l}\text { Make use of grammar and vocabulary formation rules to get the meaning of new words in a reading } \\
\text { passage? }\end{array}$ & 2.84 & 1.081 \\
\hline 23 & Find the meaning of a new word by dividing it into parts that I understand? & 3.13 & 1.129 \\
\hline 24 & Try to translate what I read into my own language in order to understand a reading passage? & 3.62 & 1.238 \\
\hline 25 & Try to transfer new words in English into my own language to get their meaning? & 2.56 & 1.268 \\
\hline 26 & Take notes of important information while reading a passage? & 2.81 & .931 \\
\hline 27 & Make summaries of information that I read? & 3.06 & 1.014 \\
\hline 28 & Highlight the major points using colors, underlining, capital letters, circles, bold writing, italics, etc.? & 3.44 & 1.190 \\
\hline \multicolumn{2}{|c|}{ Compensation Strategies } & 3.11 & .746 \\
\hline 29 & Understand unfamiliar English words by making guesses using suffixes, prefixes, and word order? & 2.94 & 1.105 \\
\hline 30 & $\begin{array}{l}\text { Use forms of address, background knowledge, text organization, structural clues, and description of } \\
\text { people to understand new words in a text? }\end{array}$ & 3.06 & .982 \\
\hline 31 & Make up new words if I do not know the right ones while summarizing a passage? & 3.09 & 1.445 \\
\hline 32 & Try to understand a reading passage without looking up every new word? & 3.34 & 1.260 \\
\hline \multicolumn{2}{|c|}{ Metacognitive Strategies } & 3.18 & .715 \\
\hline 33 & Overview the next reading text by previewing questions and vocabulary, and pictures? & 2.91 & 1.118 \\
\hline 34 & Pay attention when someone is reading a passage? & 3.13 & 1.070 \\
\hline 35 & Try to find as many ways as I can to read? & 3.03 & 1.402 \\
\hline 36 & Notice my mistakes and use that information to help me do better in reading in future? & 3.53 & 1.191 \\
\hline 37 & Have clear objectives and goals for improving my reading skills? & 3.44 & .840 \\
\hline 38 & Decide the purpose of reading? & 3.41 & .875 \\
\hline 39 & Try to find out how to be a better reader? & 3.00 & .842 \\
\hline 40 & Plan my schedule so I will have enough time to read? & 2.91 & .928 \\
\hline 41 & Look for people I can talk to about what I read? & 3.38 & 1.185 \\
\hline 42 & Look for opportunities to read as much as possible? & 2.91 & .995 \\
\hline 43 & Assess my progress in learning reading skills? & 3.41 & 1.214 \\
\hline \multicolumn{2}{|c|}{ Affective Strategies } & 3.02 & .758 \\
\hline 44 & $\begin{array}{l}\text { Reduce anxiety about learning reading using relaxation, deep breathing, laughter, games, mediation, } \\
\text { and music? }\end{array}$ & 3.16 & 1.322 \\
\hline 45 & Make positive statements about myself after completing a reading task? & 3.13 & 1.264 \\
\hline 46 & Encourage myself to read even when I am afraid of making a mistake? & 3.84 & .847 \\
\hline 47 & Give myself a reward to treat when I do well in reading? & 3.00 & 1.218 \\
\hline 48 & Use a checklist to discover feelings, attitudes, and motivation after doing a reading task? & 2.59 & 1.160 \\
\hline 49 & Notice if I am tense or nervous when I read? & 3.19 & 1.378 \\
\hline 50 & Write down my feelings about learning reading in a diary? & 2.59 & 1.316 \\
\hline 51 & Talk to someone else about how I feel toward learning reading? & 2.69 & 1.091 \\
\hline \multicolumn{2}{|c|}{ Social Strategies } & 3.22 & .826 \\
\hline 52 & Ask the other person to slow down or say it again if I do not understand something in reading? & 2.78 & 1.008 \\
\hline 53 & Ask people whose English is better than mine to correct me when 1 read? & 3.41 & 1.160 \\
\hline 54 & Practice English with other students? & 3.44 & 1.294 \\
\hline 55 & Ask for help from good speakers of English when doing a reading task? & 3.34 & 1.335 \\
\hline 56 & Ask questions about a reading passage? & 2.81 & 1.230 \\
\hline 57 & Try to read about the culture of English speakers? & 3.53 & 1.191 \\
\hline 58 & Be aware about the author's feelings and thoughts in a reading passage? & 3.22 & 1.263 \\
\hline \multicolumn{2}{|r|}{ Overall } & 3.03 & .593 \\
\hline
\end{tabular}

1. Could you list the smartphones' tools, applications, and features that help you learn reading skills?

2. Are you allowed to use the smartphone inside the classroom?

3. Do you think that you need training on how to employ the reading strategies and smartphone in learning reading skills? If yes, 
4. What are the strategies and smartphone features you think you need training on?

Thank you.

\section{Copyrights}

Copyright for this article is retained by the author(s), with first publication rights granted to the journal.

This is an open-access article distributed under the terms and conditions of the Creative Commons Attribution license (http://creativecommons.org/licenses/by/4.0/). 